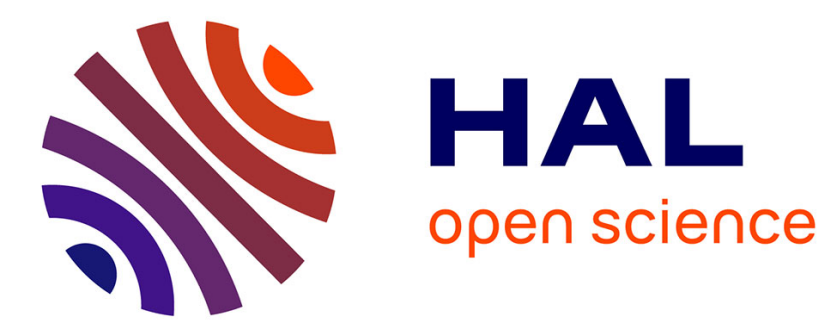

\title{
Photochemistry of glycolaldehyde in cryogenic matrices
}

\author{
W. Chin, M. Chevalier, R. Thon, R. Pollet, J. Ceponkus, C. Crépin
}

\section{To cite this version:}

W. Chin, M. Chevalier, R. Thon, R. Pollet, J. Ceponkus, et al.. Photochemistry of glycolaldehyde in cryogenic matrices. Journal of Chemical Physics, 2014, 140 (22), pp.224319. 10.1063/1.4881605. hal-01157652

\section{HAL Id: hal-01157652 \\ https://hal.science/hal-01157652}

Submitted on 23 Aug 2016

HAL is a multi-disciplinary open access archive for the deposit and dissemination of scientific research documents, whether they are published or not. The documents may come from teaching and research institutions in France or abroad, or from public or private research centers.
L'archive ouverte pluridisciplinaire HAL, est destinée au dépôt et à la diffusion de documents scientifiques de niveau recherche, publiés ou non, émanant des établissements d'enseignement et de recherche français ou étrangers, des laboratoires publics ou privés. 


\section{ADP Tournal of Chemical Physics}

\section{Photochemistry of glycolaldehyde in cryogenic matrices}

W. Chin, M. Chevalier, R. Thon, R. Pollet, J. Ceponkus, and C. Crépin

Citation: The Journal of Chemical Physics 140, 224319 (2014); doi: 10.1063/1.4881605

View online: http://dx.doi.org/10.1063/1.4881605

View Table of Contents: http://scitation.aip.org/content/aip/journal/jcp/140/22?ver=pdfcov

Published by the AIP Publishing

\section{Articles you may be interested in}

Optimal geometries and harmonic vibrational frequencies of the global minima of water clusters $(\mathrm{H} 2 \mathrm{O}) \mathrm{n}, \mathrm{n}=$ $2-6$, and several hexamer local minima at the $\operatorname{CCSD}(\mathrm{T})$ level of theory

J. Chem. Phys. 139, 114302 (2013); 10.1063/1.4820448

Infrared spectra and ultraviolet-tunable laser induced photochemistry of matrix-isolated phenol and phenol-d 5 J. Chem. Phys. 136, 024505 (2012); 10.1063/1.3666018

Spectroscopic and computational studies of matrix-isolated iso-CHBr3: Structure, properties, and photochemistry of iso-bromoform

J. Chem. Phys. 135, 124503 (2011); 10.1063/1.3640887

Vibrational dynamics of $\mathrm{N}-\mathrm{H}, \mathrm{C}-\mathrm{D}$, and $\mathrm{C} \mathrm{O}$ modes in formamide

J. Chem. Phys. 124, 064508 (2006); 10.1063/1.2162165

On the photoisomerization of 5-hydroxytropolone: An abinitio and nuclear wave function study

J. Chem. Phys. 107, 6275 (1997); 10.1063/1.474344

\section{A|P| $\left.\right|_{\text {Applied Physics }} ^{\text {Journal of }}$}

Journal of Applied Physics is pleased to announce André Anders as its new Editor-in-Chief 


\title{
Photochemistry of glycolaldehyde in cryogenic matrices
}

\author{
W. Chin, ${ }^{1, \text { a) }}$ M. Chevalier, ${ }^{1}$ R. Thon, ${ }^{1}$ R. Pollet,${ }^{2}$ J. Ceponkus, ${ }^{3}$ and C. Crépin ${ }^{1}$ \\ ${ }^{1}$ Institut des Sciences Moléculaires d'Orsay, CNRS UMR 8214, Université Paris-Sud, 91405 Orsay, France \\ ${ }^{2}$ DSM/IRAMIS/SIS2M (CEA-CNRS UMR3299), Commissariat à l'Énergie Atomique, \\ 91191 Gif-sur-Yvette, France \\ ${ }^{3}$ Department of General Physics and Spectroscopy, Vilnius University, 01315 Vilnius, Lithuania
}

(Received 28 January 2014; accepted 23 May 2014; published online 13 June 2014)

\begin{abstract}
The photochemistry of glycolaldehyde (GA) upon irradiation at $266 \mathrm{~nm}$ is investigated in argon, nitrogen, neon, and para-hydrogen matrices by IR spectroscopy. Isomerization and fragmentation processes are found to compete. The hydrogen-bonded Cis-Cis form of GA is transformed mainly to the open Trans-Trans conformer and to $\mathrm{CO}$ and $\mathrm{CH}_{3} \mathrm{OH}$ fragments and their mixed complexes. Different photo-induced behaviours appear depending on the matrix. In nitrogen, small amounts of Trans-Gauche and Trans-Trans conformers are detected after deposition and grow together upon irradiation. The Trans-Gauche conformer is characterized for the first time. In para-hydrogen due to a weaker cage effect additional $\mathrm{H}_{2} \mathrm{CO}$ and $\mathrm{HCO}$ fragments are seen. Calculations of the potential energy surfaces of $S_{0}, S_{1}$, and $T_{1}$ states - to analyse the torsional deformations which are involved in the isomerization process - and a kinetic analysis are presented to investigate the different relaxation pathways of GA. Fragmentation of GA under UV irradiation through the $\mathrm{CO}+\mathrm{CH}_{3} \mathrm{OH}$ molecular channel is a minor process, as in the gas phase. () 2014 AIP Publishing LLC. [http://dx.doi.org/10.1063/1.4881605]
\end{abstract}

\section{INTRODUCTION}

Because they are widely present in the atmosphere, the fate of carbonyl compounds upon ultraviolet radiation has attracted numerous studies. ${ }^{1}$ When subject to electronic excitation, carbonyl compounds can dissociate to highly reactive species and undergo many cascade reactions by combining to radicals. Glycolaldehyde $\left(\mathrm{HOCH}_{2} \mathrm{CHO}, \mathrm{GA}\right)$ is one such product (Fig. 1). Its photochemistry in the gas phase was extensively studied. Photo-dissociation in atmospheric conditions was found to yield many end-products such as formaldehyde $\left(\mathrm{H}_{2} \mathrm{CO}\right)$, methanol $\left(\mathrm{CH}_{3} \mathrm{OH}\right)$, carbon monoxide $(\mathrm{CO})$, glyoxal $(\mathrm{CHOCHO})$, formic acid $(\mathrm{HCOOH})$, and carbon dioxide $\left(\mathrm{CO}_{2}\right)^{2,3}$ It is only recently that the UV photolysis of pure GA in the gas phase was studied. ${ }^{4}$ Photolysis end-products are similar to those previously observed in air except that $\mathrm{CO}_{2}$ is missing and intermediate products, i.e., hydroxyl $(\mathrm{OH})$ and formyl $(\mathrm{HCO})$ radicals were detected using cavity ring down spectroscopy. Four channels were considered in these previous works as first steps of photodissociation, of which three involve the formation of radicals:

$$
\begin{aligned}
& \mathrm{HOCH}_{2} \mathrm{COH}+h v \rightarrow \mathrm{HCO}+\mathrm{CH}_{2} \mathrm{OH}, \\
& \mathrm{HOCH}_{2} \mathrm{COH}+h v \rightarrow \mathrm{OH}+\mathrm{CH}_{2} \mathrm{CHO}, \\
& \mathrm{HOCH}_{2} \mathrm{COH}+h v \rightarrow \mathrm{H}+\mathrm{HOCH}_{2} \mathrm{CO}, \\
& \mathrm{HOCH}_{2} \mathrm{COH}+h v \rightarrow \mathrm{CO}+\mathrm{CH}_{3} \mathrm{OH} .
\end{aligned}
$$

\footnotetext{
a) Author to whom correspondence should be addressed. Electronic mail: wutharath.chin@u-psud.fr
}

In the gas phase, the major relaxation pathway is the $\alpha$ $\mathrm{CC}$ bond cleavage (Norrish type I reaction) (channel 1). In atmospheric conditions and depending on the wavelengths of the irradiation, ${ }^{3}$ it accounts for $65 \%-80 \%$ of the end-products. The formation of $\mathrm{CH}_{3} \mathrm{OH}$ molecules reveals that the direct molecular elimination channel (4) also occurs $(\sim 10 \%)$ while channel 3 accounts for less than 15\%. In Zhu et al. experiments where GA is photolysed without air, the molecular channel (4) is also observed but is much less efficient than channel 1 which is predominant. ${ }^{4}$ The ratios of endproduct molecules relative to the GA photolysed at $308 \mathrm{~nm}$ are estimated to $41 \%, 60 \%, 10 \%, 7 \%$, and $7 \%$ for $\mathrm{H}_{2} \mathrm{CO}$, $\mathrm{CO},(\mathrm{CHO})_{2}, \mathrm{HCOOH}$, and $\mathrm{CH}_{3} \mathrm{OH}$, respectively. The radical pathways are supported by the recent theoretical study of Cui et al. who calculated the potential energy profiles in the $\mathrm{S}_{0}$ ground state, the excited $\mathrm{S}_{1}$ singlet, and $\mathrm{T}_{1}$ triplet states of GA considering the three $\mathrm{C}-\mathrm{C}, \mathrm{C}-\mathrm{H}$, and $\mathrm{C}-\mathrm{O}$ bond cleavage channels upon excitation of the most stable form. ${ }^{5}$ They propose that after excitation to $S_{1}$, GA relaxes to $T_{1}$ through intersystem crossing due to a high $\mathrm{S}_{1} / \mathrm{T}_{1}$ spin-orbit coupling $\left(23.4 \mathrm{~cm}^{-1}\right)$. Because the $T_{1}$ state is adiabatically correlated with the radicals' ground-state along these three cleavage channels, GA dissociates to radicals. They also find that the predominant channel is the production of HCO (channel 1), and that channel 3 is nearly closed, supporting previous studies. $^{2-4}$

GA molecule mainly appears as a pseudo-cyclic form named CC (Cis-Cis) with an intramolecular H-bond. According to theory, this $\mathrm{CC}$ form is the most stable conformer but three "open" conformers, i.e., with no H-bond, are also stable, lying at higher energies: TT, TG, and CT forms ${ }^{5-8}$ (Fig. 1). The $\mathrm{CC}$ geometry refers to the cis configurations of the $\mathrm{CO} / \mathrm{C}=\mathrm{O}$ and $\mathrm{OH} / \mathrm{CC}$ groups with respect to the $\mathrm{C}-\mathrm{C}$ 

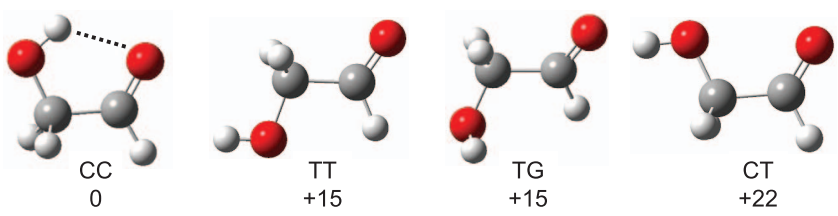

FIG. 1. The four stable conformers of GA: CC, TT, TG, and CT. Relative energies are given in kJ/mol (B3LYP/def2-TZVPP method, this study). Carbon atoms are in grey, oxygen in red, and hydrogen in white. The dotted line represents the internal hydrogen-bond of CC.

and $\mathrm{C}-\mathrm{O}$ bonds, respectively. The TT and TG forms display Trans-Trans and Trans-Gauche configurations and are found nearly isoenergetic, TT being slightly lower in energy. ${ }^{6}$ The CT (Cis-Trans) conformer is the highest in energy and differs from $\mathrm{CC}$ by the rotation of the $\mathrm{OH}$ group.

This study aims at investigating the photochemistry of GA in different cryogenic solids, spanning from the classical matrices (nitrogen, argon, and neon) to the softer parahydrogen medium. The behaviour of GA upon irradiation at $266 \mathrm{~nm}$ may differ from that in the gas phase. The photochemistry of carbonyl compounds in cryogenic solids often leads to different end-products or complexes due to the matrix cage effect and the recombination of geminate precursors. Furthermore, an earlier study evidenced the formation of the TT conformer from the CC form upon broadband IR irradiation in rare gas matrices. ${ }^{9}$ Because such environments make it possible to trap metastable species such as intermediate products or higher energy conformers, we seek to document the elementary steps of the photolysis of GA and investigate the effect in a confined environment.

The article is organised as follows: we describe the experimental and theoretical methods used in this work; results are presented in Sec. III which reports spectroscopic data before and after UV irradiation; a kinetic analysis of the photoproducts and excited state calculations considering the photoisomerization channel for the different conformers of GA are also described; the discussion in Sec. IV focuses on the matrix host effects and on relaxation channels in matrices.

\section{METHODOLOGIES}

\section{A. Experimental}

Three different cryogenic setups were used for matrix isolation experiments, of which two cryostats based at ISMO (Orsay, France) were dedicated to spectroscopy in the midIR region for argon (Ar) and nitrogen $\left(\mathrm{N}_{2}\right)$ for one setup, and for neon $(\mathrm{Ne})$ and para-hydrogen $\left(\mathrm{pH}_{2}\right)$ matrices for another setup. Details about the setups at ISMO are described in earlier works. ${ }^{10,11}$ Matrices were deposited onto $\mathrm{CaF}_{2}$ window kept at $17 \mathrm{~K}$ for $\mathrm{Ar}$ and $20 \mathrm{~K}$ for $\mathrm{N}_{2}$ in a Displex closedcycle cryostat. Experiments in $\mathrm{pH}_{2}$ were run in a helium bath cryostat coupled with a converter filled with a catalyst for ortho/para conversion. ${ }^{11}$ The $\mathrm{pH}_{2}$ matrices were deposited directly from the converter onto a diamond window kept at $4.2 \mathrm{~K}$. For Ne matrices, the same setup as for $\mathrm{pH}_{2}$ was used; the carrier gas was first passed through the converter at $50 \mathrm{~K}$ then condensed onto the deposition window. A small immer- sion helium cryostat (IHC-3) hosted at the MAX-Lab (Lund University, Sweden) was used for experiments in the far-IR region for $\mathrm{Ne}$ and $\mathrm{pH}_{2}$ solids. Matrices were deposited on a gold plated OFHC copper mirror cooled to $2.8 \mathrm{~K}$. Due to the heat load from incoming sample, gas temperature increased to $3.6 \mathrm{~K}$ during the deposition. When the deposition was stopped, the temperature immediately dropped to $2.8 \mathrm{~K}$. Spectra were obtained at $2.8 \mathrm{~K}$, directly after deposition.

GA powder (Fluka, $>98 \%$ ) is a covalent dimer crystal that dissociates to monomeric species upon heating at $60^{\circ} \mathrm{C}$. GA molecules are entrained by the flow of the carrier gas. The behaviour of GA upon UV excitation is monitored by FourierTransform IR spectroscopy. The setups used did not allow precise estimation of GA absolute concentration. A rough estimate for GA/host ratio was $\sim 2 / 1000$. IR spectra were measured with a Nicolet Nexus 670/870 FTIR-spectrometer at $0.25 \mathrm{~cm}^{-1}$ resolution in the $600-5000 \mathrm{~cm}^{-1}$ spectral region and a $\mathrm{LN}_{2}$-cooled MCT detector in Orsay. A Bruker IFS 120 spectrometer at 1 and $0.1 \mathrm{~cm}^{-1}$ resolutions in the $30-600 \mathrm{~cm}^{-1}$ range using a globar light source equipped with a $6 \mu \mathrm{m}$ Mylar beamsplitter and LHe-cooled Si bolometer was used for experiments in Lund. An optical $650 \mathrm{~cm}^{-1}$ cutoff filter was placed in front of the bolometer in order to minimise noise in the spectra.

UV irradiation studies were performed at ISMO. The UV sources consisted of two $266 \mathrm{~nm}$-quadrupled Nd:YAG laser (Quantel), one operating at $10 \mathrm{~Hz}$ and the other (Brio Quantel) at $20 \mathrm{~Hz}$. The latter was used in experiments in $\mathrm{Ne}$ and $\mathrm{pH}_{2}$. The laser bandwidth was $\sim 0.01 \mathrm{~nm}$ and typical laser power used for irradiation was $\sim 10 \mathrm{~mW}$. The size of the laser spot was larger than the deposition window so that the whole matrix sample was irradiated by the UV light. Electronic absorption spectra were recorded with a spectrometer (Jobin-Yvon) equipped with a broadband photomultiplier (Hamamatsu) using a deuterium discharge lamp as light source.

\section{B. Theoretical methods}

To explore the $S_{0}, S_{1}$, and $T_{1}$ potential energy surfaces (PES), the TURBOMOLE package was used. ${ }^{12}$ Geometries of $S_{0}$ electronic state for the four conformers of GA were fully optimized using density functional theory (DFT), while time-dependent (TD)-DFT was used to study $\mathrm{S}_{1}$ and $\mathrm{T}_{1}$ electronic states. All calculations were performed in $\mathrm{C} 1$ symmetry with the B3LYP exchange-correlation functional and the triple-zeta doubly-polarised def2-TZVPP basis set to ensure a fine convergence of the excited states properties. In addition, the two-dimensional PES defined by the two OCCO and $\mathrm{CCOH}$ dihedral angles of $\mathrm{S}_{0}, \mathrm{~S}_{1}$, and $\mathrm{T}_{1}$ states were computed on a grid with $15^{\circ}$ intervals. About 325 calculations were, thus, carried out per PES, from $-180^{\circ}$ to $180^{\circ}$ for OCCO and from $-180^{\circ}$ to $0^{\circ}$ for $\mathrm{CCOH}$. The whole PESs were then reconstructed taking advantage of molecular symmetry. Each point of the grid corresponds to geometries where all other degrees of freedom of the molecule were optimized. As mentioned above a more precise exploration was performed in the regions of energy minima.

Full geometry optimisation and frequencies calculations were run for the structures obtained at energy minima on the 
three PESs. Vibrational frequency calculations give no imaginary value and indicate real minima for all structures. In addition, such calculations were performed for complexes of GA with a $\mathrm{N}_{2}$ molecule in the ground state at the B3LYP/def2TZVPP level of theory including the $\mathrm{D} 3$ dispersion correction with Becke-Johnson damping proposed by Grimme. ${ }^{13}$

\section{RESULTS}

\section{A. Spectroscopy of as-deposited samples}

\section{IR spectra}

IR spectra of GA in $\mathrm{pH}_{2}, \mathrm{Ne}, \mathrm{Ar}$, and $\mathrm{N}_{2}$ matrices in selected regions are displayed in Fig. 2 and Fig. S1 in the supplementary material. ${ }^{28}$ In all matrices, the H-bonded CC conformer is observed in accord with previous studies in rare gas and $\mathrm{H}_{2}$ solids. ${ }^{9} 11$ Experimental frequencies in $\mathrm{pH}_{2}, \mathrm{Ne}$, Ar, and $\mathrm{N}_{2}$ are listed in Table I. They are compared to gas phase values ${ }^{14}$ and theoretical calculations. ${ }^{7}$ Gas-to-matrix shifts are mode- and host-dependent; the weakest spectral shifts are in Ne. The $\mathrm{OH}$ stretch $(\nu \mathrm{OH})$ mode is red-shifted $\left(\sim 3540 \mathrm{~cm}^{-1}\right)$ compared to a free $\mathrm{OH}$ group due to the intramolecular H-bond. The largest red-shift is measured in

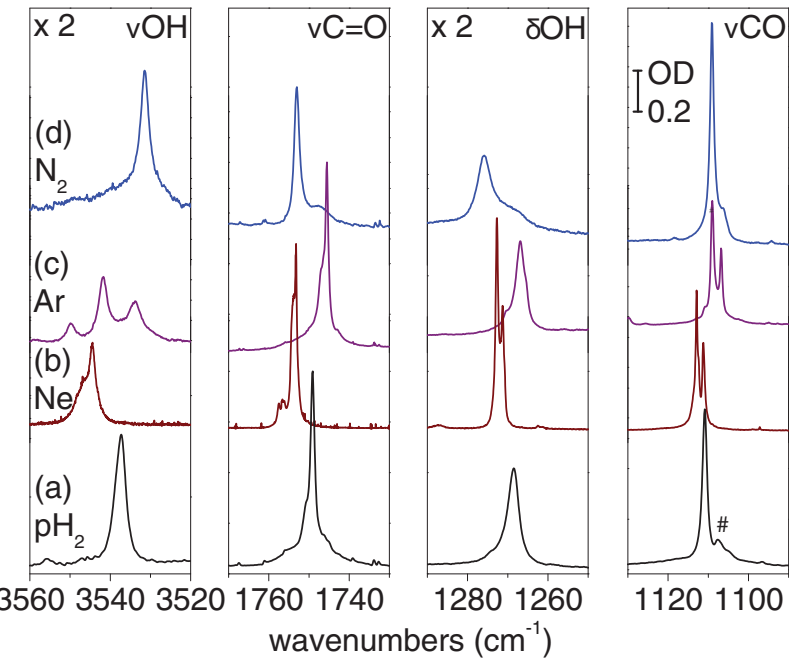

FIG. 2. Vibrational bands selected from IR spectra before irradiation of GA isolated in (from bottom to top): (a) $\mathrm{pH}_{2}$, (b) $\mathrm{Ne}$, (c) $\mathrm{Ar}$, (d) $\mathrm{N}_{2}$. The \# symbol indicates band of dimers of GA.

$\mathrm{N}_{2}$ and can be correlated with the blue-shift and the relative broadening of the in-plane $\mathrm{OH}$ bending mode $(\delta \mathrm{OH}$ $\sim 1275 \mathrm{~cm}^{-1}$ ) (Fig. 2(d)): these features are in favour of a

TABLE I. Experimental vibrational frequencies $\left(\mathrm{cm}^{-1}\right)$ of the CC conformer of GA in para-hydrogen, neon, argon, and nitrogen matrices. ${ }^{\mathrm{a}}$ Only the main absorption is reported in the case of structured bands due to site effects. Gas-phase frequencies are taken from Ref. 14. Calculated anharmonic frequencies $\left(\mathrm{cm}^{-1}\right)$ and intensities indicated in brackets $(\mathrm{km} / \mathrm{mol})$ are taken from Ref. 7. Additional calculated low frequencies are from Ref. 8. Mode numbering is the same as in Ref. 7. The mode description is simplified, especially in the spectral ranges where anharmonic coupling is important.

\begin{tabular}{|c|c|c|c|c|c|c|c|}
\hline \multicolumn{8}{|c|}{ CC conformer } \\
\hline \multirow[b]{2}{*}{ Mode } & \multicolumn{5}{|c|}{ Experimental } & \multicolumn{2}{|c|}{ Theoretical } \\
\hline & Gas phase $^{b}$ & $\mathrm{pH}_{2}$ & $\mathrm{Ne}$ & $\mathrm{Ar}$ & $\mathrm{N}_{2}$ & $\mathrm{CC} / / \mathrm{B} 3$ & Description $^{\mathrm{c}}$ \\
\hline v 18 & 3549 & 3538 & 3544.4 & 3542 & 3532 & $3570(54)$ & $v \mathrm{OH}$ \\
\hline $2 * v 13$ & & 2901 & & 2910 & 2904.5 & 2913 (14) & \\
\hline v 17 & 2881 & 2882 & 2883.2 & 2895 & 2894 & 2898 (13) & $v_{\mathrm{as}} \mathrm{CH}_{2}$ \\
\hline$v 12+v 13$ & & & 2864 & 2880 & & $2883(9)$ & \\
\hline $2 * v 12$ & & & 2854 & & & $2816(14)$ & \\
\hline$v 16$ & 2840 & 2850 & 2838.6 & 2854 & 2868 & $2874(11)^{\mathrm{d}}$ & $v_{\mathrm{s}} \mathrm{CH}_{2}$ \\
\hline v 15 & 2820 & 2837 & 2828 & 2846 & 2863.4 & 2854 (19) & $v \mathrm{CH}$ \\
\hline $2 * v 11$ & 2710 & 2707.3 & 2707.7 & 2713.3 & 2720.9 & $2707(6)$ & \\
\hline$v 14$ & 1754 & 1749.7 & 1753.3 & 1746.5 & 1753.7 & $1761(108)$ & $v \mathrm{C}=\mathrm{O}$ \\
\hline $2 * v 6$ & 1706 & 1702.5 & 1706.4 & 1697 & 1714.5 & $1716(33)$ & \\
\hline$v 13$ & 1456 & 1424 & 1431.5 & 1443 & 1435.5 & 1454 (11) & sc. $\mathrm{CH}_{2}$ \\
\hline$v 12$ & 1425 & 1409 & 1408.4 & 1400 & 1414 & $1421(27)$ & w. $\mathrm{CH}_{2}, \delta \mathrm{OH}$ \\
\hline $2 * v 4$ & 1378 & 1398 & 1393.0 & 1400 & 1400.5 & $1412(10)$ & \\
\hline$v 11$ & 1356 & 1363.7 & 1364.1 & 1365.6 & 1369.9 & $1363(31)$ & $\delta \mathrm{CH}$ \\
\hline v 10 & 1275 & 1269.6 & 1272.1 & 1267.8 & 1276.8 & $1273(41)$ & $\delta \mathrm{OH}$, w. $\mathrm{CH}_{2}$ \\
\hline$v 9$ & & 1229 & & 1228 & 1233 & $1225(3)$ & tw. $\mathrm{CH}_{2}$ \\
\hline$v 8$ & 1112 & 1111.1 & 1112.9 & 1110.0 & 1110.1 & $1120(80)$ & $v \mathrm{CO}$ \\
\hline$v 6$ & 859 & 859.4 & 860.9 & 855.6 & 867.6 & 865 (49) & $v \mathrm{CC}$ \\
\hline$v 5$ & 752 & 750.4 & 752 & 750.9 & 755.4 & $758(9)$ & Backbone \\
\hline$v 4$ & & & & & & $713(0)$ & r. $\mathrm{CH}_{2}$ \\
\hline$v 3$ & $360.3^{\mathrm{e}}$ & 365 & 360.9 & $341^{\mathrm{f}}$ & & $356^{\mathrm{g}}$ & $\gamma \mathrm{OH}$ \\
\hline$v 2$ & $282.4^{\mathrm{e}}$ & 281.9 & 287.0 & $274^{\mathrm{f}}$ & & $276^{\mathrm{g}}$ & $\mathrm{H}$ bond \\
\hline$v 1$ & $207.6^{\mathrm{e}}$ & 216.5 & & & & $210^{\mathrm{g}}$ & $\gamma \mathrm{CC}$ \\
\hline
\end{tabular}

${ }^{a}$ Weak differences appear between this work and our previous results in Ref. 11. The accuracy is better in the present work as obtained by assignment after photolysis.

${ }^{\mathrm{b}}$ Taken from Ref. 14.

${ }^{\mathrm{c}} \delta$ : bend, $\gamma$ : torsion, $v$ : stretch, r: rock, sc: scissor, tw: twist, w: wag, as: asymmetric, s: symmetric.

${ }^{\mathrm{d}}$ This theoretical value is assigned to $\left(2^{*} v 4+v 13\right)$ in Ref. 7 where $v_{\mathrm{s}} \mathrm{CH}_{2}$ is found to be involved in more than five vibrational bands.

${ }^{\mathrm{e}} \mathrm{T}$. Huet, private communication.

${ }^{\mathrm{f}}$ Taken from Ref. 9.

${ }^{\mathrm{g}}$ Taken from Ref. 8. 
strengthening of the internal $\mathrm{H}$-bond of $\mathrm{CC}$ in $\mathrm{N}_{2}$. GA is too large a molecule to occupy a single substitutional site of the host lattices and site effects can be seen as multiplets in Ar or as doublet structures in $\mathrm{Ne}$ (traces c and b of Fig. 2). Strong anharmonic couplings occur between vibrational modes in the $\mathrm{CC}$ conformer as illustrated in the 1400 and $2800 \mathrm{~cm}^{-1}$ regions (see Fig. $\mathrm{S}^{28}$ ), where band intensity distributions and spectral shifts depend on the nature of the matrix. Assignment in these two regions as given in Table I is based on calculations from Ref. 7. Weak features due to dimeric species or small aggregates of GA can be observed in all matrices (marked with a hash sign in Fig. 2 and Fig. $\mathrm{S}^{28}$ ) but their amount varies with the deposition conditions. They are easily distinguished from $\mathrm{CC}$ conformer as they do not react with the excitation laser and hence do not perturb the irradiation process.

$\mathrm{CC}$ is the only conformer detected in $\mathrm{pH}_{2}, \mathrm{Ne}$, and $\mathrm{Ar}$ right after deposition but unexpected bands are also observed in $\mathrm{N}_{2}$ at $3668,3644, \sim 1078$, and $1028 \mathrm{~cm}^{-1}$. We carefully checked that they were not induced by the globar source of the FTIR spectrometer. Bands at 3668 and $3644 \mathrm{~cm}^{-1}$ are the $\nu \mathrm{OH}$ signatures of two additional conformers of GA adopting an open structure (Fig. S2 in the supplementary material ${ }^{28}$ ). They are present at a similar but very weak amount $(<2 \%)$ and grow upon UV irradiation. These bands belong to the TT and TG conformers. Positions and attributions of these lines were confirmed after UV irradiation of the sample which led to the formation of these conformers.

\section{UV absorption spectra}

In order to check the electronic excitation wavelength of $\mathrm{GA}$ in matrices, we measured its electronic spectrum in $\mathrm{Ar}$ and $\mathrm{N}_{2}$. UV spectra of $\mathrm{CC}$ in both matrices strongly resemble that in the gas phase ${ }^{2-4}$ or in solution ${ }^{15}$ for which the maximum absorption appears near $280 \mathrm{~nm}$. In matrices, the spectrum consists of a broadband $(40 \mathrm{~nm}$ fwhm) centred at $275 \mathrm{~nm}$ (Fig. 3). This suggests that the cryogenic environment does not significantly affect the electronic properties of

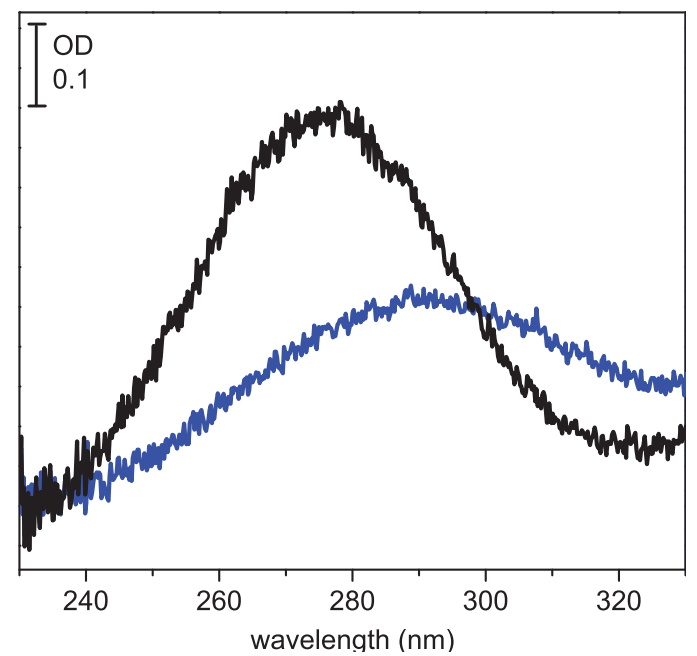

FIG. 3. UV absorption spectra of GA in nitrogen before (black) and after irradiation (blue) at $266 \mathrm{~nm}$.

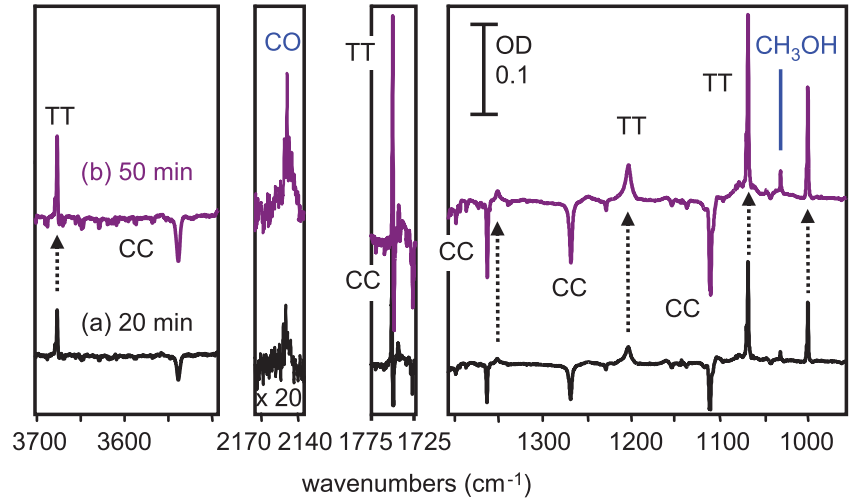

FIG. 4. Difference spectra of GA in $\mathrm{pH}_{2}$ after (a) $20 \mathrm{~min}$ and (b) $50 \mathrm{~min}$ of $266 \mathrm{~nm}$ irradiation at $\sim 10 \mathrm{~mW}$ laser power. Dotted arrows refer to TT (black).

the molecule. Hence, the $266 \mathrm{~nm}$ wavelength used for the irradiation experiments is strongly resonant with the absorption of $\mathrm{CC}$ in matrices and should efficiently excite the $\mathrm{CC}$ conformer.

\section{B. Photochemistry of glycolaldehyde: Products}

Products formed upon $266 \mathrm{~nm}$ irradiation in cryogenic solids consist of fragments and isomers. The overall behaviour of IR spectra measured at different irradiation times is similar in all solids: the $\mathrm{CC}$ bands decrease and new bands due to the photo-products appear. Figures 4-7 show difference spectra in $\mathrm{pH}_{2}, \mathrm{Ne}, \mathrm{Ar}$, and $\mathrm{N}_{2}$, respectively. Negative bands refer to CC. Two different groups were distinguished based on the change in the bands intensity. Bands of open conformers increase upon irradiation then decrease - except in $\mathrm{Ne}$ - and bands of dissociation products grow more slowly and continuously along irradiation.

\section{Open conformers}

Open conformers are observed in all matrices. $\mathrm{In}_{\mathrm{pH}}$, $\mathrm{Ne}$, and Ar, only the TT conformer is detected (Figs. 4-6). All weak bands that follow the same kinetics as the $\nu \mathrm{CO}$ and vOH TT bands $\left(\sim 1070\right.$ and $\left.\sim 3670 \mathrm{~cm}^{-1}\right)$ are attributed to TT.

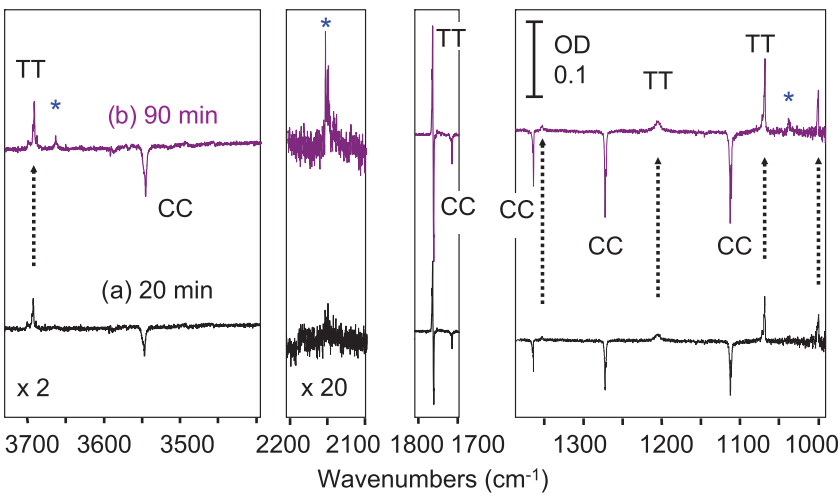

FIG. 5. Difference spectra of GA in Ne after (a) $20 \mathrm{~min}$ and (b) $90 \mathrm{~min}$ of 266 $\mathrm{nm}$ irradiation at $\sim 10 \mathrm{~mW}$ laser power. The ${ }^{*}$ sign represents $\mathrm{CH}_{3} \mathrm{OH}-\mathrm{CO}$ complex. Dotted arrows refer to TT (black). 


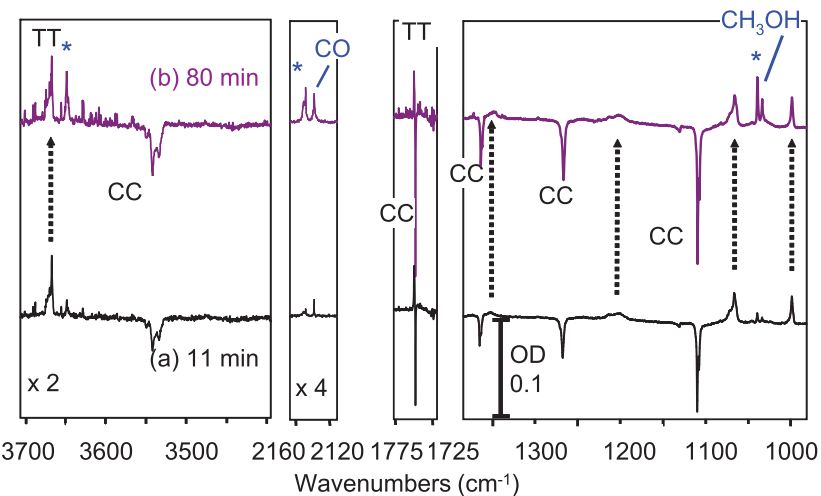

FIG. 6. Difference spectra of GA in Ar after (a) $11 \mathrm{~min}$ and (b) $80 \mathrm{~min}$ of 266 $\mathrm{nm}$ irradiation at $\sim 10 \mathrm{~mW}$ laser power. The ${ }^{*}$ sign represents $\mathrm{CH}_{3} \mathrm{OH}-\mathrm{CO}$ complex. Dotted arrows refer to TT (black).

Their experimental frequencies are given in Table II. As expected, the $\nu \mathrm{OH}$ frequency is higher than that of $\mathrm{CC}$ in agreement with the opening of the internal H-bond. Our assignment of TT agrees well with calculated anharmonic frequencies ${ }^{7,8}$ and earlier studies. ${ }^{9}$

TT conformer is also observed in $\mathrm{N}_{2}$ (Table II) but several absorptions which do not come from TT grow concomitantly with TT (Fig. 7). They belong to the TG conformer. Bands at $1076,1051.5$, and $1028 \mathrm{~cm}^{-1}$ give a satisfactory agreement with the $\nu \mathrm{CO}$, coupling of $\mathrm{CH}_{2}$ twist with $\delta \mathrm{CH}$, and $\nu \mathrm{CC}$ calculated frequencies of TG as reported in Ref. 7 (1079, 1049, and $1023 \mathrm{~cm}^{-1}$ respectively, see also Table III). The examination of experimental and calculated $\nu \mathrm{OH}$ spectral shifts between CC and TG $\left(\Delta v_{\exp }=112 \mathrm{~cm}^{-1}, \Delta v_{\text {th }}=133 \mathrm{~cm}^{-1}\right)$ and between TG and TT $\left(\Delta v_{\exp }=24 \mathrm{~cm}^{-1}, \Delta v_{\text {th }}=37 \mathrm{~cm}^{-1}\right)$ allows attributing the $3644 \mathrm{~cm}^{-1}$ band to TG $v \mathrm{OH}$ mode. Absorptions in the 1400 and $2800 \mathrm{~cm}^{-1}$ regions $\left(\mathrm{CH}\right.$ and $\mathrm{CH}_{2}$ stretches and bends) are not well resolved and are very close to TT bands. Our assignment, also based on Ref. 7, should therefore be considered tentative for these bands (Table III).

Taking advantage of the $266 \mathrm{~nm}$ irradiation to increase the concentration of TT conformer in the matrix, we were able to measure its electronic absorption spectrum. In $\mathrm{Ar}$, it consists of a broad band centred at $\sim 307 \mathrm{~nm}$. The $266 \mathrm{~nm}$

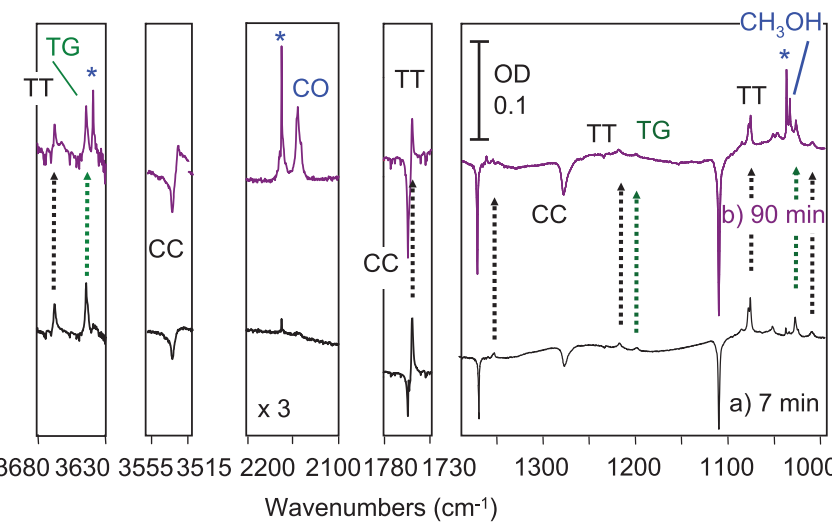

FIG. 7. Difference spectra of GA in $\mathrm{N}_{2}$ after (a) 7 min and (b) 90 min of $266 \mathrm{~nm}$ irradiation at $\sim 10 \mathrm{~mW}$ laser power. The * sign represents $\mathrm{CH}_{3} \mathrm{OH}-$ CO complex. Dotted arrows refer to TT (black), TG (green).
TABLE II. Experimental vibrational frequencies $\left(\mathrm{cm}^{-1}\right)$ of the TT conformer of GA in para-hydrogen, neon, argon, and nitrogen matrices. Only the main absorption is reported in case of structured bands due to site effects. Calculated anharmonic frequencies $\left(\mathrm{cm}^{-1}\right)$ and intensities indicated in brackets $(\mathrm{km} / \mathrm{mol})$ are taken from Ref. 7. Additional calculated low frequency is from Ref. 8. Mode numbering is the same as in Ref. 7.

\begin{tabular}{|c|c|c|c|c|c|c|}
\hline \multicolumn{7}{|c|}{ TT conformer } \\
\hline \multirow[b]{2}{*}{ Mode } & \multicolumn{4}{|c|}{ Experimental } & \multicolumn{2}{|c|}{ Theoretical } \\
\hline & $\mathrm{pH}_{2}$ & $\mathrm{Ne}$ & $\mathrm{Ar}$ & $\mathrm{N}_{2}$ & $\mathrm{CC} / / \mathrm{B} 3$ & Description $^{\mathrm{a}}$ \\
\hline$v 18$ & 3677.4 & 3690.7 & 3668 & 3668 & $3740(36)$ & $v \mathrm{OH}$ \\
\hline v 17 & 2919 & 2920 & 2925 & 2919 & $2921(15)$ & $v_{\text {as }} \mathrm{CH}_{2}$ \\
\hline$v 16$ & 2826 & 2828 & 2835 & 2834 & $2863(10)$ & $v_{\mathrm{s}} \mathrm{CH}_{2}$ \\
\hline$v 15$ & 2815 & 2809 & 2810 & 2822 & $2823(35)$ & $v \mathrm{CH}$ \\
\hline$v 14$ & 1752.1 & 1756.2 & 1750.7 & 1753.5 & $1770(145)$ & $v \mathrm{C}=\mathrm{O}$ \\
\hline$v 13$ & & 1442 & 1438 & 1441.5 & $1458(12)$ & sc. $\mathrm{CH}_{2}$ \\
\hline$v 11$ & 1352.2 & 1353 & 1350.4 & 1352 & $1354(4)$ & $\delta \mathrm{CH}$ \\
\hline$v 9$ & 1203.8 & 1204 & 1203 & 1217 & $1203(68)$ & $\delta \mathrm{OH}$, w. $\mathrm{CH}_{2}$ \\
\hline$v 7$ & 1067.7 & 1068.4 & 1066.6 & 1078 & $1083(63)$ & $v \mathrm{CO}$ \\
\hline$v 6$ & 1000.1 & 1000.3 & 998.8 & 1010 & 994 (46) & $v \mathrm{CC}$ \\
\hline$v 4$ & $540^{\mathrm{b}}$ & $539.6^{\mathrm{b}}$ & $538^{\mathrm{c}}$ & & $540(6)$ & Backbone \\
\hline$v 3$ & $342.9^{\mathrm{b}}$ & $334^{\mathrm{b}}$ & $331^{\mathrm{c}}$ & & $323^{\mathrm{d}}$ & Backbone \\
\hline
\end{tabular}

${ }^{a} \delta$ : bend, $v$ : stretch, sc: scissor, w: wag, as: asymmetric, s: symmetric.

${ }^{\mathrm{b}}$ Recorded at the MAX-Lab, where CC $\rightarrow$ TT isomerization was observed under IR irradiation.

${ }^{\mathrm{c}}$ Taken from Ref. 9

${ }^{\mathrm{d}}$ Taken from Ref. 8

laser should, thus, weakly excite TT. The same measurement was performed in $\mathrm{N}_{2}$. A maximum centred at $307 \mathrm{~nm}$ is also observed, suggesting that the electronic transition energy is similar in TT and TG (as predicted by calculations, see below). The electronic spectrum after irradiation in $\mathrm{N}_{2}$ is displayed in Fig. 3 (blue), also showing the UV spectrum before irradiation (black). The absorption band is clearly red-shifted, corresponding to the decrease of CC concomitantly with the appearance of TT and TG. The UV absorption of open conformers is, thus, obtained from the blue curve after subtraction of the contribution of the $\mathrm{CC}$ conformer.

TABLE III. Experimental vibrational frequencies $\left(\mathrm{cm}^{-1}\right)$ of the TG conformer of GA in nitrogen matrices. Calculated anharmonic frequencies $\left(\mathrm{cm}^{-1}\right)$ and intensities indicated in brackets $(\mathrm{km} / \mathrm{mol})$ are taken from Ref. 7. Mode numbering is the same as in Ref. 7.

\begin{tabular}{lccc}
\hline \hline & \multicolumn{2}{c}{ TG conformer } \\
\cline { 3 - 4 } Mode & Experimental & $\mathrm{CC} / / \mathrm{B} 3$ & Description $^{\mathrm{a}}$ \\
\hline$v 18$ & $\mathrm{~N}_{2}$ & $3703(27)$ & $v \mathrm{OH}$ \\
$v 16$ & 3644 & $2918(16)$ & $v_{\mathrm{s}} \mathrm{CH}_{2}$ \\
$v 15$ & 2919 & $2794(23)$ & $v \mathrm{CH}$ \\
$v 14$ & 2822 & $1764(137)$ & $v \mathrm{C}=\mathrm{O}$ \\
$v 13$ & 1749 & $1361(16)$ & $\delta \mathrm{CH}$ \\
$v 11$ & 1352 & $1182(15)$ & tw. $\mathrm{CH} \mathrm{H}_{2}$ \\
$v 9$ & 1199 & $1079(66)$ & $v \mathrm{CO}$ \\
$v 8$ & 1076 & $1049(32)$ & tw. $\mathrm{CH}_{2}, \delta \mathrm{CH}$ \\
$v 6$ & 1051.5 & $1023(29)$ & $v \mathrm{CC}$ \\
\hline \hline
\end{tabular}

${ }^{\mathrm{a}} \delta$ : bend, $v$ : stretch, tw: twist, as: asymmetric, s: symmetric. 
TABLE IV. Vibrational frequencies $\left(\mathrm{cm}^{-1}\right)$ of the photo-dissociation products (most intense bands) formed upon photolysis of GA at $266 \mathrm{~nm}$. Frequencies with no decimal values indicate the centre of broad absorptions. The sign indicates that bands are not observed in the matrix.

\begin{tabular}{|c|c|c|c|c|}
\hline & $\mathrm{pH}_{2}$ & $\mathrm{Ne}$ & $\mathrm{Ar}$ & $\mathrm{N}_{2}$ \\
\hline \multirow[t]{3}{*}{$\mathrm{CO}$} & 2142.9 & - & 2138.5 & 2139.8 \\
\hline & 3679.5 & & 3670.7 & 3679.4 \\
\hline & 3000 & & 3004 & 3001.6 \\
\hline \multirow[t]{4}{*}{$\mathrm{CH}_{3} \mathrm{OH}$} & 2951.7 & - & 2954 & 2954 \\
\hline & 2840.8 & & 2844.7 & 2844.5 \\
\hline & 1031.1 & & 1033.7 & 1033.7 \\
\hline & - & 3662.5 & 3649.8 & 3638.3 \\
\hline \multirow{3}{*}{$\mathrm{CO}-\mathrm{CH}_{3} \mathrm{OH}$} & 2154 & 2154 & 2148.7 & 2152.9 \\
\hline & 1036.3 & 1038.4 & 1039.4 & 1040.4 \\
\hline & & & & 1037.3 \\
\hline \multirow{2}{*}{$\mathrm{H}_{2} \mathrm{CO}$} & 2782.6 & & & \\
\hline & 1742.6 & - & - & - \\
\hline \multirow{2}{*}{$\mathrm{HCO}$} & 2449.2 & - & - & 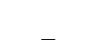 \\
\hline & 1864.5 & - & - & - \\
\hline
\end{tabular}

\section{Dissociation products}

The fragments formed during the photolysis are mainly composed of isolated carbon monoxide (CO) and methanol $\left(\mathrm{CH}_{3} \mathrm{OH}\right)$ molecules, and of their molecular complexes and aggregates. Frequencies are summarised in Table IV.

In $\mathrm{Ar}$ and $\mathrm{N}_{2}$ isolated $\mathrm{CO}$ and $\mathrm{CH}_{3} \mathrm{OH}$ molecules and 1:1 molecular complexes appear simultaneously. More intense $\mathrm{CO}: \mathrm{CH}_{3} \mathrm{OH}$ bands indicate that complexes are predominant $\left(\mathrm{I}\left(\mathrm{CH}_{3} \mathrm{OH}\right) / \mathrm{I}\left(\mathrm{CH}_{3} \mathrm{OH}: \mathrm{CO}\right)=0.6\right.$ for the $\nu \mathrm{CO}$ band of $\mathrm{CH}_{3} \mathrm{OH}$ ) (Figs. 6 and 7). In our experiments in $\mathrm{Ne}$ there is only a very small amount of fragments consisting essentially of $\mathrm{CO}: \mathrm{CH}_{3} \mathrm{OH}$ complexes showing a singlet band at $1038.4 \mathrm{~cm}^{-1}$ and a multiplet near $2154 \mathrm{~cm}^{-1}$ (Fig. 5). In $\mathrm{pH}_{2}$, in contrast with the other matrices, isolated $\mathrm{CO}$ and $\mathrm{CH}_{3} \mathrm{OH}$ molecules are by far more abundant than complexes as evidenced in Fig. 4(b). The multiplet structure of CO bands is in accord with the rotational structure of the molecule in $\mathrm{pH}_{2}{ }^{16}$ but some weak bands also belong to complexes or aggregates. Figure S3 in the supplementary material ${ }^{28}$ displays a zoom in the $\mathrm{CO}$ band region near $2140 \mathrm{~cm}^{-1}$. Other striking differences observed in $\mathrm{pH}_{2}$ are given by traces of $\mathrm{H}_{2} \mathrm{CO}$ formaldehyde at $2782.6 \mathrm{~cm}^{-1}$ (symmetric $\nu \mathrm{CH}$ ) and 1742.6 $\mathrm{cm}^{-1}(\nu \mathrm{C}=\mathrm{O})$, and by very weak bands of $\mathrm{HCO}$ formyl radical at $1864.5 \mathrm{~cm}^{-1}(\nu \mathrm{C}=\mathrm{O})$ and $2449.2 \mathrm{~cm}^{-1}(\nu \mathrm{CH})$ (Fig. $\mathrm{S} 4$ in the supplementary material ${ }^{28}$ ). The presence of $\mathrm{H}_{2} \mathrm{CO}$ in $\mathrm{pH}_{2}$ matrix was confirmed by comparing frequencies and relative intensities after GA photolysis with a reference spectrum acquired for plain $\mathrm{H}_{2} \mathrm{CO}$ in $\mathrm{pH}_{2}$.

\section{Photochemistry of glycolaldehyde: Kinetics}

To quantify the different relaxation channels upon excitation of GA, a kinetic analysis was done in the different matrices. IR spectra were measured at different irradiation times to obtain the time evolution of the photo-products. Laser intensity was kept constant in all experiments but the total initial concentration of GA could have varied from one experiment to the other.
Irradiation effect was monitored by measuring integrated intensities of some bands as a function of irradiation time. The whole spectrum was considered for $\mathrm{CC}$ as well as the $\nu$ CO mode. The same mode at $\sim 1068 \mathrm{~cm}^{-1}$ was used for TT conformer and absorptions of monomeric $\mathrm{CO}$ and $\mathrm{CH}_{3} \mathrm{OH}$ molecules and their complexes were taken in the $2139-2150 \mathrm{~cm}^{-1}$ and $1033-1040 \mathrm{~cm}^{-1}$ regions. Relative concentrations were obtained from integrated intensities using the Beer's law. Preliminary vibrational excitation experiments on $\mathrm{CC}$ in Ar enabled us to relate the molar absorption coefficients $\varepsilon T T$ to $\varepsilon C C$, i.e., $\varepsilon T T / \varepsilon C C=0.87$ for $\nu C O$. This value is close to the 0.78 value issued from calculated intensities within the anharmonic approach. ${ }^{7}$ For $\mathrm{CO}$ or $\mathrm{CH}_{3} \mathrm{OH}$, monomeric species and complexes were considered and a mean value was adjusted imposing that the total concentration of GA and products must stay constant. This procedure was used in classical matrices but, in $\mathrm{pH}_{2}$, partial evaporation of the matrix did not allow us to perform complete kinetics. In $\mathrm{N}_{2}$, TT and TG display similar behaviour upon irradiation, as checked on their $\nu \mathrm{OH}$ bands and they were treated as a single species arbitrarily referred to as TT. Their calculated band intensities for $\nu \mathrm{CO}$ mode are very close ${ }^{7}\left(63\right.$ and $66 \mathrm{~km} \mathrm{~mol}^{-1}$ in Tables II and III).

GA kinetics shows similar trends in $\mathrm{Ar}$ and $\mathrm{N}_{2}$ : CC decreases while TT grows up to a maximum and then decreases (Figs. 8(a) and 8(b)). In both matrices and in $\mathrm{pH}_{2}$ the depletion of CC leads to completion. It is a consequence of a minor but irreversible mechanism, i.e., fragmentation. Fragments are produced from the very beginning of the photolysis at a significant amount in $\mathrm{Ar}$ and $\mathrm{N}_{2}$ (Figs. 6-8). In Ne, CC and TT seem to reach equilibrium in our experimental conditions and only small amounts of fragments are produced (Figs. 5 and $8(c))$. In fact, no concentration can be given for the fragments in Ne because of their very low band intensities in the IR spectra. Isomerization and fragmentation processes for $\mathrm{CC}$ and TT are taken into account, respectively characterized by $\left(k_{i}, k_{-i}\right)$
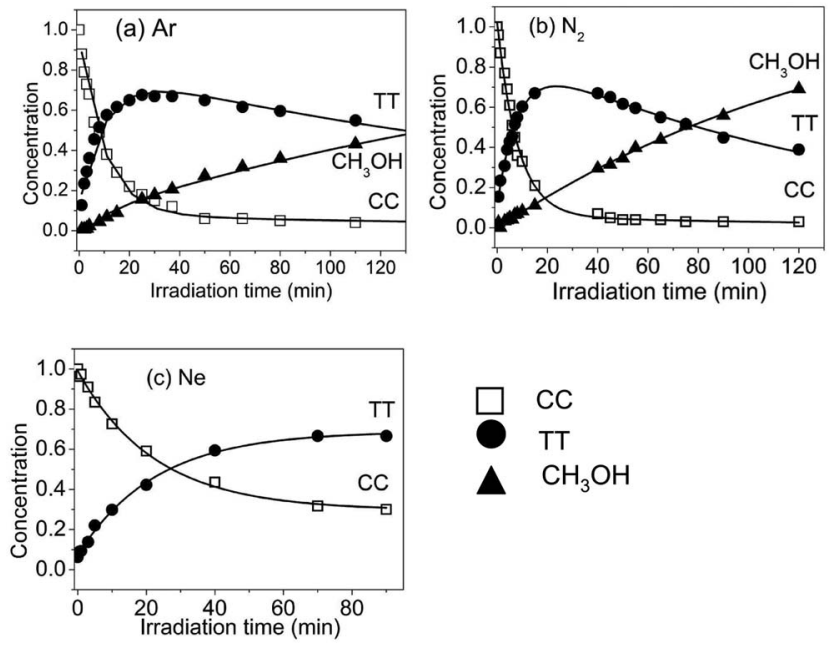

FIG. 8. Time evolution of the relative concentrations of $\mathrm{CC}$ (squares) and TT-plus TG in $\mathrm{N}_{2}$-(circles) conformers of $\mathrm{GA}$ and $\mathrm{CH}_{3} \mathrm{OH}$ (triangles) in (a) Ar, (b) $\mathrm{N}_{2}$, and (c) Ne. Solid lines are fits obtained from Eq. (9), keeping the same $k_{+}$and $k_{-}$parameters for the three species in each host. The $266 \mathrm{~nm}$ laser power was kept constant at $\sim 10 \mathrm{~mW}$. 
TABLE V. Rate constants $\left(\mathrm{min}^{-1}\right)$ obtained from the kinetic analysis of the photolysis of GA, as described in Eqs. (5)-(8), upon $266 \mathrm{~nm}$ irradiation at $\sim 10 \mathrm{~mW}$ laser power.

\begin{tabular}{lccc}
\hline \hline & $\mathrm{Ar}$ & $\mathrm{N}_{2}$ & $\mathrm{Ne}$ \\
\hline$k_{i}$ & 0.070 & 0.090 & 0.030 \\
$k_{-i}$ & 0.010 & 0.005 & 0.014 \\
$k_{C}$ & 0.010 & 0.006 & 0.001 \\
$k_{T}$ & 0.003 & 0.006 & 0.001 \\
\hline \hline
\end{tabular}

and $\left(k_{C}, k_{T}\right)$ rate constants. The kinetic equations are

$$
\begin{gathered}
C C \stackrel{k_{i}}{\longrightarrow} T T, \\
T T \stackrel{k_{-i}}{\longrightarrow} C C, \\
C C \stackrel{k_{C}}{\longrightarrow} \mathrm{CO}+\mathrm{CH}_{3} \mathrm{OH}, \\
T T \stackrel{k_{T}}{\longrightarrow} \mathrm{CO}+\mathrm{CH}_{3} \mathrm{OH} .
\end{gathered}
$$

Each step is considered as elementary. Solving the kinetic equations leads to Eq. (9) which expresses the concentration $C_{i}(t)$ of each $i$ species as a sum of two exponential functions involving the same $k_{+}$and $k_{-}$rate constants for all species plus a constant value,

$$
C_{i}(t)=A_{i 1} \exp \left(-k_{+} t\right)+A_{i 2} \exp \left(-k_{-} t\right)+A_{i 3},
$$

where $A_{i 1}, A_{i 2}$, and $A_{i 3}$ parameters are characteristic of each species $i$. The $k_{+}$and $k_{-}$constants are defined as follows:

$$
\begin{aligned}
k_{+} & =\left(k_{i}+k_{C}+k_{-i}+k_{T}+\Delta^{1 / 2}\right) / 2, \\
k_{-} & =\left(k_{i}+k_{C}+k_{-i}+k_{T}-\Delta^{1 / 2}\right) / 2, \\
\Delta & =\left(k_{i}+k_{C}+k_{-i}+k_{T}\right)^{2}-4\left[\left(k_{i}+k_{C}\right)\left(k_{-i}+k_{T}\right)-k_{i} k_{-i}\right] \\
& =\left[\left(k_{i}+k_{C}\right)-\left(k_{-i}+k_{T}\right)\right]^{2}+4 k_{i} k_{-i} .
\end{aligned}
$$

Figure 8 displays the corresponding fitting curves as solid lines. The rate constants obtained with $\sim 10 \mathrm{~mW}$ laser power are listed in Table V. From our measurements, determination of $k_{i}$ is more accurate. Estimated uncertainties are about $10 \%$ for $k_{i}$ and are at least $20 \%$ for the other rate constants that are one or two orders of magnitude lower.

The rate constants reflect a combination of diverse and complex processes: photolysis of isolated GA, relaxation of electronically and/or vibrationally excited GA, host effects on GA and photoproducts, etc. Two main effects can be underlined from Table V: isomerization is the major process following CC excitation $\left(k_{i} \gg k_{C}\right)$, and CC displays a higher photo-reactivity at $266 \mathrm{~nm}$ than the open conformers $\left(k_{i}+k_{C}\right.$ $\gg k_{-i}+k_{T}$ ). In fact, the latter effect simply results from the less efficient excitation of open conformers, as shown by the UV absorption spectra (Fig. 3). The $k_{C}$ and $k_{T}$ rate constants are comparable in $\mathrm{N}_{2}$ but in Ar, $k_{C}>k_{T}$. In these matrices, fragmentation occurs from both CC and TT conformers. Only qualitative trends can be given in $\mathrm{pH}_{2}$. TT appears at early irradiation times but $\mathrm{CO}$ and $\mathrm{CH}_{3} \mathrm{OH}$ appear later. In fact, they grow very slowly and seem to follow the increase of TT, suggesting that they are essentially produced from TT.

\section{Theoretical results}

We here focus on the isomerization channels accessible with a $266 \mathrm{~nm}$ excitation. Aldehydic compounds easily undergo intersystem crossing (ISC) from $\mathrm{S}_{1}$ to $\mathrm{T}_{1}$ upon electronic excitation. ${ }^{17}$ This is also the case of GA as estimated by the spin-orbit coupling $\left(23.4 \mathrm{~cm}^{-1}\right)$ calculated in Ref. 5 for the structure at the minimum energy on $S_{1}$. As a consequence, calculations were performed on both $S_{1}$ and $T_{1}$ states. Since isomerization mainly consists of rotations around the backbone of GA, $\mathrm{CCOH}$ and OCCO dihedrals were varied to construct the two-dimensional PES of $\mathrm{S}_{0}, \mathrm{~S}_{1}$, and $\mathrm{T}_{1}$ states.

\section{1. $S_{0}$ ground-state calculations}

The most stable CC conformer is stabilised by a hydrogen-bond with a distance of $2.13 \AA$ between the hydroxyl hydrogen and the carbonyl oxygen. TT and TG conformers are very close in energy $(15 \mathrm{~kJ} / \mathrm{mol}$ from CC) and the highest CT conformer is $22 \mathrm{~kJ} / \mathrm{mol}$ above CC (Fig. 1). These values are in excellent agreement with those obtained with the CASSCF/cc-pVDZ method, ${ }^{5}$ with the MP4(SDTQ)/ccpVQZ method, ${ }^{6}$ and with the CCSD(T)/cc-pVTZ//B3LYP/6$31 \mathrm{G}(\mathrm{d}, \mathrm{p})$ hybrid quartic force field. ${ }^{7}$ Energies and dihedrals of the four conformers are listed in Table VI.

Our method, therefore, succeeds in capturing the structural and energetic properties of GA conformers at a limited computational cost, which is required in order to perform extensive calculations of PES. The torsional barriers between the conformers were calculated along the minimum energy paths and agree within $2 \mathrm{~kJ} / \mathrm{mol}$ with the values obtained with the MP4(SDTQ)/cc-pVQZ method. ${ }^{6}$ TT and TG are separated by a small barrier $(2 \mathrm{~kJ} / \mathrm{mol})$, but it requires $9 \mathrm{~kJ} / \mathrm{mol}$ to convert to $\mathrm{CC}$. The barrier for the $\mathrm{CT} \rightarrow \mathrm{CC}$ conversion is 2 $\mathrm{kJ} / \mathrm{mol}$. The resulting surface is shown in the bottom part of Fig. 9. Note that this small CT-CC barrier can explain the nonobservation of CT in our experiments: even if they are formed upon irradiation, $\mathrm{CT}$ isomers can easily transform in $\mathrm{CC}$ by proton tunnelling.

\section{2. $S_{1}$ and $T_{1}$ excited state calculations}

a. Potential energy surfaces. The lowest singlet transition is of HOMO-LUMO character. The electron excitation proceeds from the $n$ orbital localised on the carbonyl oxygen to the $\pi^{*}$ orbital of the $\mathrm{C}=\mathrm{O}$ group. This leads to important changes in charge distributions and strengths of bonds, giving very different geometries for the energy minima in $S_{1}$ with respect to $S_{0}$. Scan of $S_{1}$-PES shows three energy basins. Each basin is also reached by full geometry optimisation on $S_{1}$ after vertical excitation from CC, TT, and TG geometries. The corresponding optimised structures are called minCC, minTT, and minTG, respectively, for the sake of simplicity (Fig. 9). Since the PES of $S_{1}$ and $T_{1}$ states share similar topologies (Table VI and Fig. 10) we refer in this paragraph to the same "minx" notation to describe the minima on $\mathrm{S}_{1}$ and $\mathrm{T}_{1}$. In particular, the $S_{1}$-minima adopt very close geometries to their $\mathrm{T}_{1}$ counterparts: dihedrals differ by less than $3^{\circ}$ and $\mathrm{C}=\mathrm{O}$ bond lengths are similar. 
TABLE VI. Dihedral angles and calculated energies $(\mathrm{kJ} / \mathrm{mol})$ of GA conformers in the ground state and in the $\mathrm{S}_{1}$ and $\mathrm{T}_{1}$ excited states. Wavelengths in nm are given in italic.

\begin{tabular}{lcccc}
\hline \hline & & & & Vert. energy kJ/mol (nm) \\
\cline { 3 - 5 } & $\angle \mathrm{OCCO}\left({ }^{\circ}\right)$ & $\angle \mathrm{CCOH}\left(^{\circ}\right)$ & $\Delta \mathrm{E}(\mathrm{kJ} / \mathrm{mol})$ & $\mathrm{S}_{1} \leftarrow \mathrm{S}_{0}$ \\
$\mathrm{CC}$ & 0 & 0 & 0 & $441(271)$ \\
$\mathrm{TG}$ & 180 & 180 & 15 & $411(291)$ \\
$\mathrm{CT}$ & -163.3 & 75.7 & 15 & $395(303)$ \\
$\operatorname{minCC~S} \mathrm{S}_{1} / \mathrm{T}_{1}$ & 0 & 180 & 22 & $424(282)$ \\
$\operatorname{minTT~S} \mathrm{T}_{1} / \mathrm{T}_{1}$ & $-73.0 /-71.5$ & $72.5 / 71.8$ & $370 / 295$ & $290 / 180(413 / 665)$ \\
$\operatorname{minTG~} \mathrm{S}_{1} / \mathrm{T}_{1}$ & $76.2 / 79.9$ & $59.1 / 56.6$ & $370 / 298$ & $282 / 174(424 / 688)$ \\
\hline \hline
\end{tabular}

Energies of minCC, minTT, and minTG in $\mathrm{S}_{1}$ and $\mathrm{T}_{1}$ with respect to CC conformer are reported in Table VI. MinCC and minTT are more stable than minTG on $\mathrm{S}_{1}$ and $\mathrm{T}_{1}$ and are quasi-isoenergetic. None of the minima presents intramolecular H-bond; details of their structures are given in the supplementary material. ${ }^{28}$ MinCC and minTT are highly distorted compared to $\mathrm{CC}$ and TT, i.e., twisted conformations with respect to the $\mathrm{C}-\mathrm{C}$ bond are favoured instead of a coplanar configuration. In contrast, minTG is structurally similar to the TG conformer (see Fig. 9 and Table VI). Note that the structures of minCC are similar to the minima obtained by Cui et al. in the $S_{1}$ and $T_{1}$ excited states ${ }^{5}$ (Table $S 1$ in the supplementary material $\left.{ }^{28}\right)$. $b$. Transition energies. Vertical and adiabatic energies between $S_{0}$ and $S_{1}$ (respectively, $T_{1}$ ) were calculated. Relevant data relative to $\mathrm{CC}$, TT, and TG are summarised in Table VI. Vertical energies for the three conformers fall under the laser excitation energy $(450 \mathrm{~kJ} / \mathrm{mol}$, corresponding to $266 \mathrm{~nm}$ ). The $\mathrm{S}_{0}-\mathrm{S}_{2} \mathrm{PES}$ is found at much higher energy $(550 \mathrm{~kJ} / \mathrm{mol})$ and cannot be reached with a single photon absorption. The predicted $\mathrm{S}_{0}-\mathrm{S}_{1}$ value for CC $(441 \mathrm{~kJ} / \mathrm{mol}$, $271 \mathrm{~nm})$ is in agreement with the electronic spectra $\left(\sim 427 \mathrm{~kJ} / \mathrm{mol}\right.$, or $280 \mathrm{~nm}$ in the gas phase $;^{4} 435 \mathrm{~kJ} / \mathrm{mol}$, $275 \mathrm{~nm}$ in this work in matrices). It is slightly blueshifted compared to the $426 \mathrm{~kJ} / \mathrm{mol}$ (B3LYP) and 421 $\mathrm{kJ} / \mathrm{mol}$ (CASPT2) values previously reported. ${ }^{5}$ The calculated

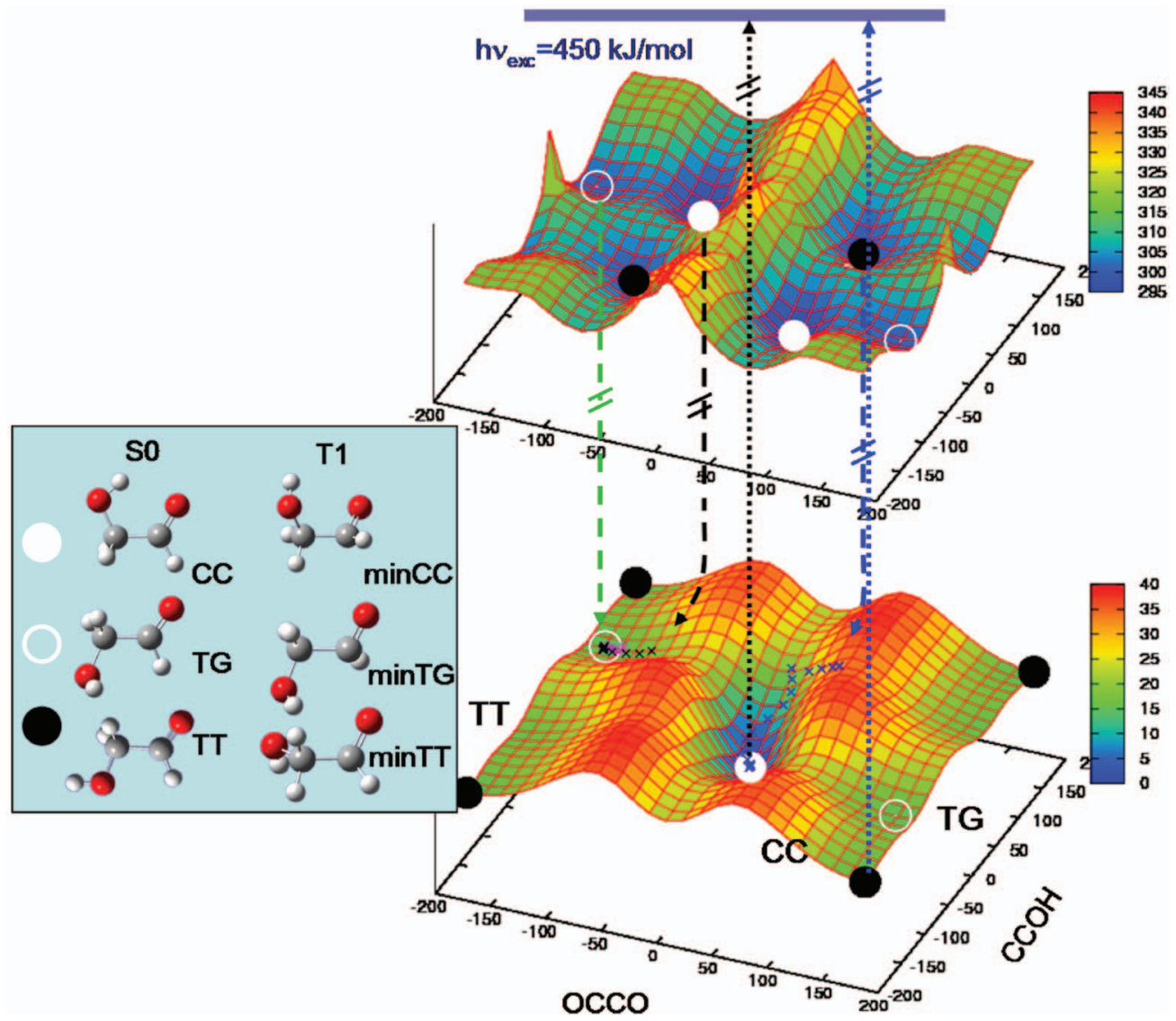

FIG. 9. Potential energy surfaces along OCCO and $\mathrm{CCOH}$ dihedrals on the $\mathrm{S}_{0}$ ground state (bottom) and $\mathrm{T}_{1}$ excited state (top) and their corresponding minima (CC and minCC are displayed in plain white circles, TG and minTG open white, and TT and minTT plain black, respectively) calculated at the B3LYP/def2TZVPP level of theory. Energy scales are in $\mathrm{kJ} / \mathrm{mol}$. Dotted arrows refer to vertical excitation of CC (black) and TT (blue). Dashed arrows refer to relaxation from $\mathrm{T}_{1}$-minCC (black), $\mathrm{T}_{1}$-minTT (blue), and $\mathrm{T}_{1}$-minTG (green), respectively. Crosses indicate relaxation pathways on the $\mathrm{S}_{0}$ surface. 


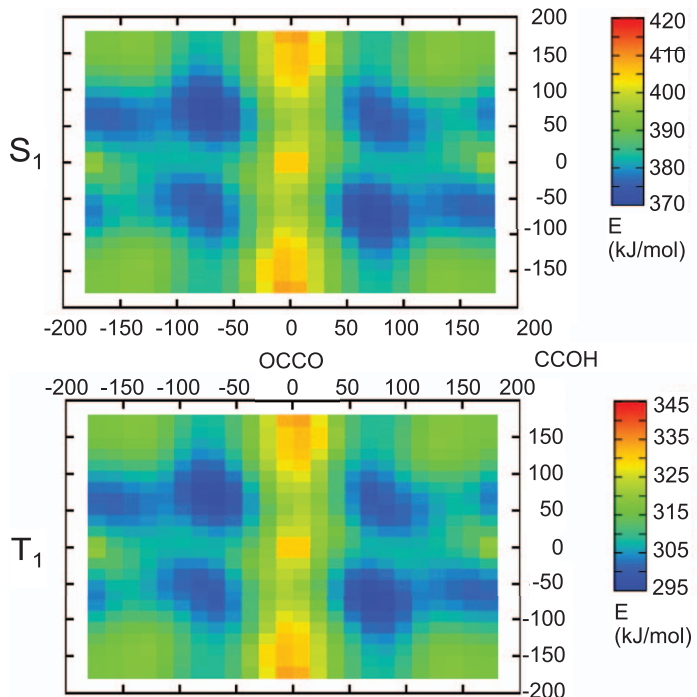

FIG. 10. Contours of $\mathrm{S}_{1}$ (top) and $\mathrm{T}_{1}$ (bottom) two-dimensional PESs along the $\mathrm{OCCO}$ and $\mathrm{CCOH}$ dihedrals showing similar topologies of both surfaces. Energies are given in $\mathrm{kJ} / \mathrm{mol}$.

transition for TT $(411 \mathrm{~kJ} / \mathrm{mol}, 291 \mathrm{~nm})$ is not far from the electronic absorption measured in matrices, approximately centred at $307 \mathrm{~nm}$. The TG conformer also absorbs in this region $(395 \mathrm{~kJ} / \mathrm{mol}, 303 \mathrm{~nm})$. Given the accuracy of the TDDFT method, ${ }^{18}$ experimental and theoretical values, therefore, appear in good agreement. Vertical emission energies from the $\mathrm{S}_{1}$ and $\mathrm{T}_{1}$ minima to the ground state are also listed in Table VI. The $\mathrm{S}_{1} \rightarrow \mathrm{S}_{0}$ (respectively, $\mathrm{T}_{1} \rightarrow \mathrm{S}_{0}$ ) transitions are predicted around $285 \mathrm{~kJ} / \mathrm{mol}$, i.e., near $420 \mathrm{~nm}$ (respectively, around $177 \mathrm{~kJ} / \mathrm{mol}, \sim 676 \mathrm{~nm}$ ), in the typical range of fluorescence spectra of many aldehydes. ${ }^{17}$ Note that the values found for $\mathrm{S}_{1}$-minCC, minTT, or minTG (from 282 to $290 \mathrm{~kJ} / \mathrm{mol}, 413-424 \mathrm{~nm}$ ) are very close to the fluorescence band measured in solution by Beeby et al. $(288 \mathrm{~kJ} / \mathrm{mol}$, $415 \mathrm{~nm}) .^{15}$

c. Relaxation pathways. Upon laser excitation, GA reaches the $S_{1}$ state with a large amount of internal energy $(\sim 80 \mathrm{~kJ} / \mathrm{mol})$. In the matrix, rapid vibrational relaxation in the electronic excited states can occur by energy transfer to the phonons. GA could, thus, relax to the three minCC, minTT, and minTG $S_{1}$-basins, these minima being very close in energy. Taking into account ISC, the system can also be brought to the corresponding $\mathrm{T}_{1}$ minima. We calculated the relaxation pathways to the ground state following radiative relaxation from the three minima in the $S_{1}$ and $T_{1}$-PESs (see Fig. 9). Since the geometries of GA at the three minima are very similar in both excited states, the relaxation channels are the same coming from $\mathrm{S}_{1}$ or $\mathrm{T}_{1}$ states. From minCC basin the system decays to a vibrational level of the ground state down to the well of TG conformer. TG is also obtained by relaxation from minTG with minor geometry changes. Decaying from minTT leads to CC conformer in the ground state. Our calculations show that only TG and CC conformers should be formed directly.

The highly distorted structures on $S_{1}$ and $T_{1}$ excited states are, therefore, possible routes to the formation of open conformers upon excitation of CC.

\section{DISCUSSION}

\section{A. Host effects}

\section{Specificity in $\mathrm{N}_{2}$}

Matrix-isolation of GA in $\mathrm{N}_{2}$ brings interesting results in terms of spectroscopy and stability of the open conformers. Only in $\mathrm{N}_{2}$ are TT and TG visible in freshly deposited matrices. It turns out that their amount varies from zero to very few percent depending on the injection conditions. This leads us to suppose that TT and TG are already present in the gas-phase mixture (GA and carrier gas) as low amount of GA-N $\mathrm{N}_{2}$ complexes since formation of complexes in a jet depends on the mixture and pressure of the gases. Following this hypothesis, we have performed calculations on GA-N 2 complexes in order to evaluate the stabilisation brought by complexation. Our results on isolated complexes for CC, TT, and TG show larger stabilisation energies for TT- $\mathrm{N}_{2}$ and TG- $\mathrm{N}_{2}$ complexes $(-7.78 \mathrm{~kJ} / \mathrm{mol}$ and $-9.13 \mathrm{~kJ} / \mathrm{mol})$ than for $\mathrm{CC}-\mathrm{N}_{2}$ $(-5.89 \mathrm{~kJ} / \mathrm{mol})$. These findings strongly suggest that the presence of $\mathrm{N}_{2}$ preferentially stabilises the open conformers.

Comparing the IR spectra in all media also gives us some hints in this direction. For instance, the $v \mathrm{OH}$ TT frequency is very sensitive to the environment: it is the lowest in $\mathrm{N}_{2}$ (also in Ar) and the highest in Ne (Table II). Actually, matrix shifts of $\mathrm{OH}$ group with respect to the gas phase are usually the weakest in $\mathrm{Ne}$ and the largest in $\mathrm{N}_{2}$ and similar behaviour was reported for several organic molecules. ${ }^{19}$ These differences can be explained by stabilising interactions of the GA molecules with the matrices, resulting from different polarisabilities of the hosts and also quadrupolar interactions for $\mathrm{N}_{2}$. We, thus, suggest that TT and TG conformers are more stabilised in $\mathrm{N}_{2}$, making it possible to observe both conformers in this specific matrix.

The low TT-TG torsional barrier $(\sim 2 \mathrm{~kJ} / \mathrm{mol})$ and the slightly higher stability of TT over TG in the free GA molecule ${ }^{6}$ can possibly induce an open pathway from TG to TT, explaining why we do not observe it in $\mathrm{pH}_{2}, \mathrm{Ne}$, and Ar. In $\mathrm{N}_{2}$, interaction with the matrix may either result in a higher barrier that would close the $\mathrm{TG} \rightarrow$ TT pathway or in a smaller energy-difference between TT and TG so that both conformers would co-exist in thermal equilibrium. The relative $v \mathrm{OH}$ band intensities of TT and TG suggest that conformers are roughly equally populated in $\mathrm{N}_{2}$ in agreement with the latter hypothesis. It should be noted that, in contrast to CT which is also separated from $\mathrm{CC}$ by a $2 \mathrm{~kJ} / \mathrm{mol}$ barrier, the $\mathrm{TG} \rightarrow \mathrm{TT}$ conversion requires more than rotation of the hydroxyl group, which can, in particular, occur through tunnelling processes as reported in matrices. ${ }^{20}$

\section{Radicals in $\mathrm{pH}_{2}$}

In the gas phase, the formation of $\mathrm{HCO}$ and $\mathrm{CH}_{2} \mathrm{OH}$ radicals ( $\mathrm{C}-\mathrm{C}$ bond cleavage) dominates the photolysis of $\mathrm{GA}$ (channel 1). No radicals were seen in classical Ar, Ne, and $\mathrm{N}_{2}$ matrices. Their absence can be explained by recombination of primary fragments in the matrix cage. The cage effect in the different matrices can be seen through the observation of $\mathrm{CH}_{3} \mathrm{OH}-\mathrm{CO}$ complexes, $\mathrm{CO}$ and $\mathrm{CH}_{3} \mathrm{OH}$ being 
photo-produced in the same matrix cage. The prominence of such complexes in Ne illustrates a very efficient process in this solid. In contrast in $\mathrm{pH}_{2}$, isolated $\mathrm{CO}$ and $\mathrm{CH}_{3} \mathrm{OH}$ molecules are mainly formed, the cage exit is made easier due to the softness of the lattice. ${ }^{21}$ Minimised geminate recombination, thus, allows detecting HCO radical - even weakly - in this peculiar solid, thereby showing that radical channels are not entirely closed. The $\mathrm{CH}_{2} \mathrm{OH}$ counterpart is not observed in $\mathrm{pH}_{2}$. According to literature, this radical can dissociate to $\mathrm{HCO}+\mathrm{CO},{ }^{22}$ or $\mathrm{H}_{2} \mathrm{CO}+\mathrm{H}^{23}$ upon UV irradiation. We suggest, thus, that this photo-dissociation occurs under our experimental conditions, which could explain the absence of $\mathrm{CH}_{2} \mathrm{OH}$ and the presence of $\mathrm{H}_{2} \mathrm{CO}$.

\section{B. Relaxation channels in matrices}

In the gas phase, four channels (Eqs. (1)-(4) are opened as first steps of photo-dissociation upon UV irradiation: ${ }^{2-4}$ channels 1-3 lead to radical fragments, channel 4 to $\mathrm{CO}$ and $\mathrm{CH}_{3} \mathrm{OH}$ molecular fragments. Following the results obtained by Zhu and Zhu, ${ }^{4}$ most of GA undergo photo-fragmentation upon UV irradiation; one can estimate that channels (1-4) represent at least $70 \%$ of the relaxation pathways. In the matrix, two types of products are detected, isomers and molecular fragments as expressed in Eqs. (5) and (7). An additional minor reaction is observed in $\mathrm{pH}_{2}$ only, leading to the production of HCO radical. The absence of radicals in Ne, Ar, and $\mathrm{N}_{2}$ may simply reflect the cage effect in the solid inducing geminate recombination of neighbouring radicals to form stable molecules, $\mathrm{GA}$ or $\mathrm{CO}+\mathrm{CH}_{3} \mathrm{OH}$. However, our results allow a deeper insight into the processes at play, as discussed in the following paragraphs.

\section{Molecular elimination}

The $\mathrm{HOCH}_{2} \mathrm{CHO}(\mathrm{GA}) \rightarrow \mathrm{CH}_{3} \mathrm{OH}+\mathrm{CO}$ molecular channel is observed in all media. It accounts at most for $10 \%$ of the gas-phase processes when considering excited GA molecules, as based on Zhu and Zhu studies, where the quantum yields of photo-fragmentation and the amount of photoproducts were measured. ${ }^{4}$ In matrices, according to the $k_{C} / k_{i}$ ratio (Table V), $\mathrm{CH}_{3} \mathrm{OH}$ and $\mathrm{CO}$ that come from $\mathrm{CC}$ only represent 3 to $14 \%$ of the products. Data relative to the return to $\mathrm{CC}$ is not available; these numbers, thus, overestimate the efficiency of the molecular channel. Yields in matrices are not much larger than in the gas phase, thereby implying that there is no enhancement of this channel in the solids. Furthermore, our calculations indicate that TT and TG conformers are more stable than the $\mathrm{CO}+\mathrm{CH}_{3} \mathrm{OH}$ dissociation limit by $2 \mathrm{~kJ} / \mathrm{mol}$. It is in favour of recombination of radicals to GA conformers at the expense of formation of $\mathrm{CO}$ and $\mathrm{CH}_{3} \mathrm{OH}$ molecules in a confined medium.

Several mechanisms may be responsible for the "direct" formation of $\mathrm{CO}$ and $\mathrm{CH}_{3} \mathrm{OH}$. An earlier theoretical study on methyl formate, a structural isomer of GA, showed that a transition state with the $\mathrm{H}$ atom bridging the carbonyl carbon and the ester oxygen could lead to $\mathrm{CO}+\mathrm{CH}_{3} \mathrm{OH} .{ }^{24}$ The analogue in the case of GA could then involve a transition state having the $\mathrm{H}$ atom shared between the $\mathrm{C}$ atoms, struc- turally similar to the hydrogen-transfer transition state of Ref. 5 (referred to as "S1-TS-PT"). Still for methyl formate, the so-called roaming mechanism implying dissociation on vibrationally hot ground state also yielded $\mathrm{CO}+\mathrm{CH}_{3} \mathrm{OH}$ but it was only observed in specific conditions and was found to be weak. ${ }^{25}$ So, we assume that molecular elimination in the matrix and in the gas phase occurs in a similar manner and with similar efficiency: the system passes through a transition state rather than through a dissociation-recombination process.

\section{Isomerization}

Isomerization occurs in matrices only. It is the dominant process as illustrated in Figs. 4-7 and by the constant rates of Table $\mathrm{V}$. It can result from two competitive pathways: (i) direct isomerization that proceeds on the PESs explored by the system or (ii) recombination of dissociation products due to the cage effect in the matrix.

Direct isomerization is due to the coupling with phonons which allows thermalisation of the system in the excited state, followed by relaxation in the ground state. This mechanism could entirely or partly quench the channels to dissociation. Similar hypothesis was proposed for acetylacetone to rationalise the differences between its photo-reactivity in the gas phase and in matrices, where similar behaviours in rare gas matrices, $\mathrm{N}_{2}$, and $\mathrm{pH}_{2}$ were observed. ${ }^{26}$ Assuming that relaxation of excited GA occurs in the electronic states by bath thermalisation and radiative transitions between the states, isomerization is a direct consequence of irradiating the molecule with UV light. Our calculations find that only $\mathrm{CC}$ and TG conformers should be formed after excitation of GA. The observation of TT, thus, likely originates from a secondary TG $\rightarrow$ TT process in the ground state due to the low TG-TT barrier. Reference 5 indicates that the system can also relax through non-radiative transitions via $S_{1} / S_{0}$ and $T_{1} / S_{0}$ conical intersections. In the gas phase, all these pathways lead to relaxation toward the most stable CC conformer but matrices stabilize the TT form (and TG form in $\mathrm{N}_{2}$ ). Direct isomerization may be seen as a step in radiative de-excitation and internal conversion in the isolated GA molecule.

Considering that fragmentation proceeds through $\mathrm{C}-\mathrm{C}$ bond cleavage, the $\mathrm{CH}_{2} \mathrm{OH}$ and $\mathrm{HCO}$ radicals can easily recombine in the matrix cage (process $i i$ ). According to theory, the corresponding transition state $(415 \mathrm{~kJ} / \mathrm{mol})$ is easily accessible under our UV excitation. ${ }^{5}$ Recombination due to the matrix cage is host-dependent: it should be the strongest in $\mathrm{Ne}$ and the weakest in $\mathrm{pH}_{2}$, on the basis of the previous discussion on the host effects. Although the complete kinetic study is not available in $\mathrm{pH}_{2}$, TT is clearly detected meaning that isomerization is at play in $\mathrm{pH}_{2}$ and has a similar efficiency as in Ne (see Figs. 4 and 5). This suggests that direct isomerization (i) of GA is more efficient than the process through recombination (ii) in all matrices.

Because of its high branching ratio, direct isomerization cannot be the simple matrix analogue of the radiative and non-radiative relaxation processes back to $\mathrm{CC}$ ground state that occur in the gas phase, where these "internal" relaxation processes represent less than $30 \%$ of the channels according to Ref. 4. Moreover, the authors clearly show that the quantum 
yield associated to $\mathrm{HCO}$ production is $\sim 60 \%$. Comparison with our observations in $\mathrm{pH}_{2}$, where TT conformer is much more abundant than $\mathrm{HCO}$, highlights a strong solvent effect quenching - although not completely - the radical dissociation channels that occur in the electronic excited states. This conclusion is in agreement with the recent work on the photodissociation of $\mathrm{N}$-methylformamide in $\mathrm{pH}_{2},{ }^{27}$ where the authors suggest that the $\mathrm{pH}_{2}$ surrounding enhances internal conversion to the ground state to explain the high ratio of the molecular channel compared to the radical pathways.

\section{Reactivity of TT and TG conformers}

As shown in the experiments, isomerization and molecular channels are also opened for the TT (and TG) conformer of GA in matrices (Eqs. (6) and (8)).

A surprising finding is the relative efficiency of the backward TT $\rightarrow$ CC conversion in Ne compared to Ar and $\mathrm{N}_{2}$ $\left(k_{i} / k_{-i}=2,7\right.$, and 18 , respectively). In fact, $k_{i}$ and $k_{-i}$ reflect a global behaviour of the sample during laser irradiation. In their study of GA in rare gas matrices, Aspiala et al. ${ }^{9} \mathrm{ob}-$ served thermal conversion from $\mathrm{TT}$ to $\mathrm{CC}$ in $\mathrm{Xe}$ and $\mathrm{Kr}$ at temperatures over $30 \mathrm{~K}$, whereas the barrier cannot be classically overcome in these conditions. With the setup used for experiments in $\mathrm{Ne}$ and $\mathrm{pH}_{2}$, thermal processes do occur, as evidenced by the partial evaporation of the $\mathrm{pH}_{2}$ matrices upon $\mathrm{UV}$ irradiation. Thus, the quite efficient backward TT $\rightarrow \mathrm{CC}$ isomerization may be partly due to a thermal effect in Ne. Such thermal effect upon irradiation cannot be completely discarded in $\mathrm{Ar}$ and $\mathrm{N}_{2}$. Nevertheless, the stronger stabilisation of TT and TG in $\mathrm{N}_{2}$ could prevent it in $\mathrm{N}_{2}$ explaining differences between $\mathrm{Ar}$ and $\mathrm{N}_{2}$.

The branching ratio between backward isomerization and molecular elimination is not known accurately, because of the weakness of these two reactions since TT is not efficiently excited at $266 \mathrm{~nm}$. Nevertheless, the $k_{-i} / k_{T}$ ratio (Table V) should more properly reflect the effect of UV irradiation on open conformers in $\mathrm{N}_{2}$ than in $\mathrm{Ar}$ and $\mathrm{Ne}$, where thermal effects may perturb the observations. It indicates that the molecular elimination is a stronger process in the photolysis of open TT and TG conformers than that of CC. The efficiency of the molecular channel depends on the relaxation pathways followed by the system in the excited and ground states. These pathways depend on the initial geometry of GA and could converge more easily to the transition state of the molecular channel when starting from an initial TT geometry than from CC. This remark is in agreement with the fact that most fragments in $\mathrm{pH}_{2}$ seem to come from TT irradiation.

\section{v. CONCLUSIONS}

We have studied the UV photolysis of GA in cryogenic matrices at $266 \mathrm{~nm}$ accompanied with excited state calculations on GA. Four different hosts have been explored in order to extract matrix effects. The IR spectroscopy of as deposited samples highlights the specificity of nitrogen matrices, where more conformers have been detected.
Upon irradiation of the $\mathrm{CC} \mathrm{H}$-bonded conformer, the open TT species is formed and stabilised in argon, neon, nitrogen, and para-hydrogen matrices. The TG conformer is also observed in nitrogen. To date, this is the first experimental evidence of the TG conformer of GA. According to calculations on the isolated molecule, TT and TG possess the same energy and are separated by a very low torsional barrier. The photo-induced formation of TG in nitrogen only is unlikely and we postulate that TG probably isomerises to TT in the other matrices studied. In addition, both conformers display similar behaviour upon deposition and irradiation in nitrogen. Following that, we conclude that TT is more stabilised in argon, neon, and para-hydrogen, while in nitrogen both TT and TG are in thermal equilibrium.

Dissociation products such as $\mathrm{CH}_{3} \mathrm{OH}, \mathrm{CO}$, and their complexes are detected in all matrices but additional $\mathrm{H}_{2} \mathrm{CO}$ and HCO radicals are detected in para-hydrogen. Despite its non-observation in classical matrices, the presence of $\mathrm{HCO}$ in the quantum solid provides clear evidence that the predominant gas-phase dissociation channel, i.e., fragmentation to $\mathrm{HCO}$ and $\mathrm{CH}_{2} \mathrm{OH}$ (CC-bond cleavage) also occurs in matrices. However, the very low concentration of HCO shows that it is nearly quenched in these environments. Dissociation to $\mathrm{CO}+\mathrm{CH}_{3} \mathrm{OH}$ is observed in all matrices but it is minor as in the gas phase. We conclude that the molecular fragments formed in matrix result from the same mechanism as in the gas phase and that cage effect is not (or only weakly) involved.

Cage effect can neither explain the efficiency of isomerization, as shown by the comparison between para-hydrogen and the other hosts. We think that isomerization is due to relaxation of GA in the excited and ground states by coupling with matrix phonons. This conclusion is supported by theoretical calculations of the excited $S_{1}$ and $T_{1}$ PES which exhibit non-planar geometries for minimum energy structures, inducing the opening of the internal H-bond. Relaxation of GA, firstly through the excited states and secondly through the ground state, can then lead to the formation of the open conformers.

The UV photo-reactivity of open TT (and TG) conformers has also been investigated. Our results show that fragmentation and isomerization also compete in the relaxation of excited open conformers. Fragmentation is not anymore a minor process, probably because of differences in the relaxation pathways through the electronic states after UV excitation. This process being irreversible, all GA is consumed at very long irradiation times and we observe a relatively high concentration of products.

\section{ACKNOWLEDGMENTS}

This work was supported by the French Research Agencies ANR (ANR-06-BLAN-0314 GOUTTELIUM), Triangle de la Physique (2010-004-T NOSTADYNE), and French-Lithuanian PHC Gilibert programme (Grant No. $25405 Y$ Y). We thank Lund National laboratory of Synchrotron Radiation MAX-lab for its support for experiments funded from European Community's Seventh Framework Programme (FP7/2007-2013) under Grant Agreement No. 
226716 and R. Lozada-Garcia for his help during the experiments in Lund. The first matrix isolation studies of GA at ISMO were carried out with P. Çarçabal and M. Broquier, and the authors acknowledge them for their involvement in the topic. The authors would also like to thank Thérèse Huet for personal communication on the gas-phase low-frequency modes of CC conformer.

${ }^{1}$ P. Carlier, H. Hannachi, and G. Mouvier, Atmos. Environ. 20(11), 2079 (1986).

${ }^{2}$ I. Magneron, A. Mellouki, G. Le Bras, G. K. Moortgat, A. Horowitz, and K. Wirtz, J. Phys. Chem. A 109(20), 4552 (2005).

${ }^{3}$ C. Bacher, G. S. Tyndall, and J. J. Orlando, J. Atmos. Chem. 39(2), 171 (2001).

${ }^{4}$ C. Z. Zhu and L. Zhu, J. Phys. Chem. A 114(32), 8384 (2010).

${ }^{5}$ G. L. Cui and W. H. Fang, Chem. Phys. Chem. 12(7), 1351 (2011).

${ }^{6}$ M. L. Senent, J. Phys. Chem. A 108(30), 6286 (2004).

${ }^{7} \mathrm{P}$. Carbonnière and C. Pouchan, Theor. Chem. Acc. 131(3), 1183 (2012).

${ }^{8}$ E. A. Bleda, I. Yavuz, Z. Altun, and C. Trindle, Int. J. Quantum Chem. 113(8), 1147 (2013)

${ }^{9}$ A. Aspiala, J. Murto, and P. Stén, Chem. Phys. 106(3), 399 (1986).

${ }^{10}$ C. Crépin and A. Tramer, Chem. Phys. 272(2-3), 227 (2001).

${ }^{11}$ J. Ceponkus, W. Chin, M. Chevalier, M. Broquier, A. Limongi, and C. Crépin, J. Chem. Phys. 133(9), 094502 (2010).

${ }^{12}$ TURBOMOLE, V6.4 2012, a development of University of Karlsruhe and Forschungszentrum Karlsruhe GmbH, 1989-2007, TURBOMOLE GmbH, since 2007, also available from http://www.turbomole.com.

${ }^{13}$ S. Grimme, J. Antony, S. Ehrlich, and H. Krieg, J. Chem. Phys. 132(15), 154104 (2010).

${ }^{14}$ M. Jetzki, D. Luckhaus, and R. Signorell, Can. J. Chem. 82(6), 915 (2004).
${ }^{15}$ A. Beeby, D. B. H. Mohammed, and J. R. Sodeau, J. Am. Chem. Soc. 109(3), 857 (1987).

${ }^{16}$ M. E. Fajardo, C. M. Lindsay, and T. Momose, J. Chem. Phys. 130(24), 244508 (2009).

${ }^{17}$ D. A. Hansen and E. K. C. Lee, J. Chem. Phys. 63(8), 3272 (1975).

${ }^{18}$ J. Fabian, L. A. Diaz, G. Seifert, and T. Niehaus, J. Mol. Struct.: THEOCHEM 594, 41 (2002).

${ }^{19}$ L. O. Paulson and D. T. Anderson, J. Phys. Chem. A 113(9), 1770 (2009); E. Isoniemi, L. Khriachtchev, M. Makkonen, and M. Räsänen, ibid. 110(40), 11479 (2006); A. J. Barnes and Z. Mielke, J. Mol. Struct. 1023, 216 (2012); S. Lopes, A. V. Domanskaya, R. Fausto, M. Räsänen, and L. Khriachtchev, J. Chem. Phys. 133(14), 144507 (2010).

${ }^{20}$ E. M. S. Maçôas, L. Khriachtchev, M. Pettersson, R. Fausto, and M. Räsänen, Phys. Chem. Chem. Phys. 7(5), 743 (2005); M. Pettersson, E. M. S. Maçôas, L. Khriachtchev, J. Lundell, R. Fausto, and M. Räsänen, J. Chem. Phys. 117(20), 9095 (2002).

${ }^{21}$ T. Momose, M. Fushitani, and H. Hoshina, Int. Rev. Phys. Chem. 24(3-4), 533 (2005).

${ }^{22}$ M. E. Jacox and D. E. Milligan, J. Mol. Spectrom. 47(1), 148 (1973).

${ }^{23}$ L. Feng, A. V. Demyanenko, and H. Reisler, J. Chem. Phys. 120(14), 6524 (2004)

${ }^{24}$ J. S. Francisco, J. Am. Chem. Soc. 125(34), 10475 (2003).

${ }^{25}$ M.-H. Chao, P.-Y. Tsai, and K.-C. Lin, Phys. Chem. Chem. Phys. 13(15), 7154 (2011)

${ }^{26}$ R. R. Lozada-Garcia, J. Ceponkus, M. Chevalier, W. Chin, J. M. Mestdagh, and C. Crépin, Phys. Chem. Chem. Phys. 14(10), 3450 (2012).

${ }^{27}$ M. Ruzi and D. T. Anderson, J. Chem. Phys. 137(19), 194313 (2012).

${ }^{28}$ See supplementary material at http://dx.doi.org/10.1063/1.4881605 for bond distances of the computed conformers of GA in the ground and excited states; complete IR spectra of GA in $\mathrm{pH}_{2}, \mathrm{Ne}, \mathrm{Ar}$, and $\mathrm{N}_{2}$ matrices; IR spectrum of TT and TG in $\mathrm{N}_{2}$ in the $\nu \mathrm{OH}$ bands region; IR spectrum of $\mathrm{GA}$ in $\mathrm{pH}_{2}$ after $110 \mathrm{~min}$ of irradiation at $266 \mathrm{~nm}$ in the $\mathrm{CO}$ bands region; IR bands of $\mathrm{HCO}$ and $\mathrm{H}_{2} \mathrm{CO}$ fragments after very long $266 \mathrm{~nm}$ irradiation of $\mathrm{GA}$ in $\mathrm{pH}_{2}$. 